\section{Surface physics not clarified}

Surface Physics of Phosphors and Semiconductors. Edited by C. G. Scott and C. E. Reed. Pp. xiv +644. (Academic: London and New York, November 1975.) £18.80; \$48.75.

THE appearance within a few months of two important books which attempt to summarise surface physics suggests that this previously murky field is now beginning to take on a clearer shape. One book (M. Prutton's Surface Physics, recently reviewed in Nature (260, 374; 1976) is a compact organised teaching instrument which deals only with clean surfaces; the other, named above, aims to give a much fuller picture, and caters largely for solid-state device physicists in pursuit of better electronic and optoelectronic devices. It is essentially a series of research reviews which, although they do not overlap greatly, do not interlock too well either.

The first 300 pages contain introductions to the theory and method of surface physics. Our understanding of surfaces has come mainly from studying specially cleaned surfaces; the structure of these has been determined by electron diffraction and spectroscopy whereas theory has been developed by extending the wave mechanics of bulk materials. This section leaves one wondering whether the experiment and theory will ever be brought together to form a proper picture of the electronic nature of a surface state, even that found at a clean vacuum-solid interface, leaving aside the much more difficult problem of the 'real' interface which is formed beneath a native or intentionally-grown oxide film. It cannot be said that this book really grasps that nettle. All the important facts are there but the authors perhaps do not work hard enough at building them into a coherent whole. To quote an example from the editors' own 100-page review of the compound semiconductors: we are told about the striking increases in surface-state concentration in gallium arsenide which are produced by washing the surface with copper ions. Why should this happen? Although the previous 80 pages has described extensive investigations of the surface of compound semiconductors, none of the 'feel' which that might have provided is used to clothe the new, intriguing experimental fact with a few shreds of explanation. One chapter, however, does take the reader gently by the hand; this is Zaininger's highly original survey of some principles of device operation which may be particularly vulnerable to the presence of unwanted surface states.
Although the term 'phosphor' appears in the title, the physics of luminescence is hardly considered at all. The greatest phosphor, zinc sulphide, in fact gets one of the shortest treatments in the book. Few gaps, however, are left in the solid-state microelectronics field (possibly Schottky barriers and electron loss spectroscopy get less than their due) and workers in this field will gain from seeing this set of reviews in juxtaposition. It will also stimulate the thought processes of any physicist working on surface effects and may even spur one of the next generation to write the book which at last pulls together the theory and practice of the physics of semiconductor surfaces.

\section{Andrew Holmes-Siedle}

\section{New mind, new body}

New Mind, New Body: Bio-Feedback: New Directions for the Mind. By Barbara B. Brown. Pp.xiii +464. (Hodder and Stoughton: London, 1975.) £5.25.

THIS book is a well written, informative, popular introduction to biofeedback. Biofeedback is a method for training a person to increase his or her control over their own physiology. Barbara Brown effectively conveys the excitement and promise of this new field. New Mind, New Body is packed with information about biofeedback and about the way our mental and emotional selves interact with our bodily selves. To make her personal point (and this is one person's view of biofeedback) Dr Brown selects the evidence, but it's a good, thoughtprovoking selection. As a popular book, its style may be a little breezy and condescending for the specialist. The references are quite thorough and will be useful to the student and professional alike.

My personal fun was reading Dr Brown's rather caustic comments on the sterility of behavioristic psychology and its total inability to deal with the links between mind and body. She levels other criticism at mechanistic physiologists who have written of their speciality as if they had it in a jar completely isolated from the rest of the whole person. She points out what happened when behavioristic psychology mistook itself for the whole of liberal arts.

Dr Brown makes sure that her role in the "founding" of the Biofeedback Research Society is clearly documented in the early chapters. Researchers in the field knew it already but the public may want to know too. Succeeding chapters are each organised around a particular physiological system. Within each chapter various biofeedback studies are discussed. This makes a readable sequence but it is not, I think, an organisation which identifies the major themes of biofeedback. For instance, mind-body and mind-brain mechanisms for learning, special effects of feedback, parameters of practice, parameters of the external feedback path, biofeedback as a system, are not discussed as salient topics.

The coverage of the bioelectric response of skin, musculature, heart, blood pressure and brain (recorded as a scalp EEG) is comprehensive. Yet, laced through the factual reporting are interpretations which range from expressions of indignation and sarcastic commentary, scientific judgments, to personal and rather woolly kinds of theories. Dr Brown really believes in mind as an object which can be studied by public science. She insists that biofeedback offers a method and that the results of biofeedback research gives a new basis for accepting the mind as a demonstrated phenomena. Her arguments are spirited, and her intentions are clear-she is not trying to pull her wool over the reader's eyes. But it is also a fact that many biofeedback researchers would make very different interpretations of the same data. For example, Dr Brown clearly believes that EEG phenomena can reveal a lot about the mind and that unique mind states are linked to unique EEGs. Yet, most users of EEG would find it difficult to defend the more conservative statement that unique brain states can be revealed in EEGs. The consensus is that the EEG doesn't provide a clue to subjective, mental life, and is a gross representation of the electrical activity of the brain.

The importance of biofeedback for training one's own physiological processes is undeniable and Dr Brown was one of the first to recognise the whole implication of this new technique. She is absolutely correct when she projects what can happen when and if humans learn how to control their own physiology by means of biofeedback.

The importance of biofeedback lies in its efficacy as a training method. Whether scientists know or agree on "how the person does it" is not really relevant to its practical value in laboratory and clinic. In fact the benefits of biofeedback are independent of the mind-brain, mind-body issue.

All-in-all it's a book worth reading. It's a personal journal produced by a lively person, with an informed mind and fearless spirit. As a popular exposition it's excellent and far ahead of its nearest rivals. T. B. Mulholland 